\title{
THE EFFECT OF VENOUS AND ARTERIAL OCCLUSION, AND SYMPATHETIC NERVE TONE, ON DIGITAL BLOOD FLOW ${ }^{1}$
}

\author{
By MILTON MENDLOWITZ, ARTHUR S. W. TOUROFF, AND HAROLD A. ABEL \\ (From the Medical Service of Dr. George Baehr, The Mount Sinai Hospital, New York, N.Y. \\ and the New York Regional Office of the Veterans Administration, New York, N.Y.)
}

(Submitted for publication July 13, 1950; accepted, October 30, 1950)

The normal range described originally (1) for blood flow in the fingertip, measured calorimetrically after vasodilatation by indirect heating, has been confirmed by Capriglione and Duque (2). Corrections for specific heat, gravity and temperature of blood (3), and the reinforcement of the effect of indirect heating by the intravenous administration of TEAC, subsequently raised the level of both normal and abnormal readings slightly. The normal range for the fingertip now is 0.25 to $0.38 \mathrm{cc} . / \mathrm{sq} . \mathrm{cm}$. of skin/min., and for the toe 0.15 to $0.29 \mathrm{cc} . / \mathrm{sq} . \mathrm{cm} . / \mathrm{min}$. (4). Venous obstruction plethysmography of the fingertip gives a normal range after indirect heating which is somewhat wider [6 to $12 \mathrm{cc} / 10 \mathrm{cc}$. of finger volume/min. (5)]. What is more, we have often observed considerable differences between single digital plethysmographic and digital calorimetric readings in the same subject under presumably similar conditions. Such discrepancies have also been noted between calorimetric and plethysmographic studies of the hand (6) especially at intermediate rates of flow, although the differences are ascribed to the "smoothing out" by the calorimeter of rapid fluctuations in flow recorded plethysmographically.

Hoobler, Avera, Little, Peet, and Bassett (7), employing the foot plethysmograph, have described considerably greater increases in blood flow during caudal anesthesia or after sympathectomy than after indirect heating, or after the intravenous injection of TEAC. These differences were attributed to the failure of indirect heat or TEAC to release sympathetic nerve tone completely. Arnott and Macfie (8), however, measuring blood flow calorimetrically, found that block-

\footnotetext{
1 Reviewed in the Veterans Administration and published with the approval of the Chief Medical Director. The statements and conclusions published by the authors are the result of their own study and do not necessarily reflect the opinion or the policy of the Veterans Administration.

This study was aided by Grants from the American Heart Association and the Research Committee of the American Medical Association.
}

ing the ulnar nerve with procaine did not increase flow in the fifth finger if sympathetic nerve tone had been previously released by indirect heat.

In an attempt to reconcile some of these discrepancies, the calorimetric method was subjected to exhaustive critical evaluation, the results of which are reported elsewhere (3). The assumptions involved in the method were sustained. It therefore seemed necessary to investigate some of the assumptions inherent in the plethysmographic method (9), the most vulnerable of these being the assumption that venous obstruction traps all the blood in the part. It also became necessary to investigate the completeness of release of sympathetic nerve tone by indirect heating supplemented by TEAC in the skin of the great toe.

\section{METHODS}

Accordingly, a series of experiments were set up wherein blood flow was measured calorimetrically after arterial and after venous obstruction, using heat supplemented by TEAC to release sympathetic nerve tone. Patients without vascular disease, and some with mild residua of "trench foot," were used as subjects. Heat was administered to the trunk by a cradle baker for from 30 to 45 minutes until positive heat balance was attained as manifested by generalized sweating. Then, TEAC (5 mg./ $\mathrm{Kg}$ ) was injected intravenously. Flow studies were begun approximately 10 minutes after the injection. For the great toe the compressing cuff was at the ankle, whereas for the fingertip (third or fourth) a Gaertner capsule was used at the proximal phalangeal joint. The arterial obstruction pressure varied between 180 and 220 and the venous obstruction pressure between 40 and 50 $\mathrm{mm}$. $\mathrm{Hg}$. Only those results were tabulated in which the flow within a minute after obstruction was at or near the original level. In approximately 10 per cent of subjects, venous obstruction produced a decrease in flow, which persisted long after release of pressure, indicating reflex vasoconstriction (see Figure 1). That psychic factors can "break through" indirect heat and less commonly through indirect heat supplemented by TEAC to produce reflex vasoconstriction is well known (10) and is demonstrated in Figure 2.

In addition, blood flow in the great toe measured calorimetrically after indirect heating and TEAC was com- 


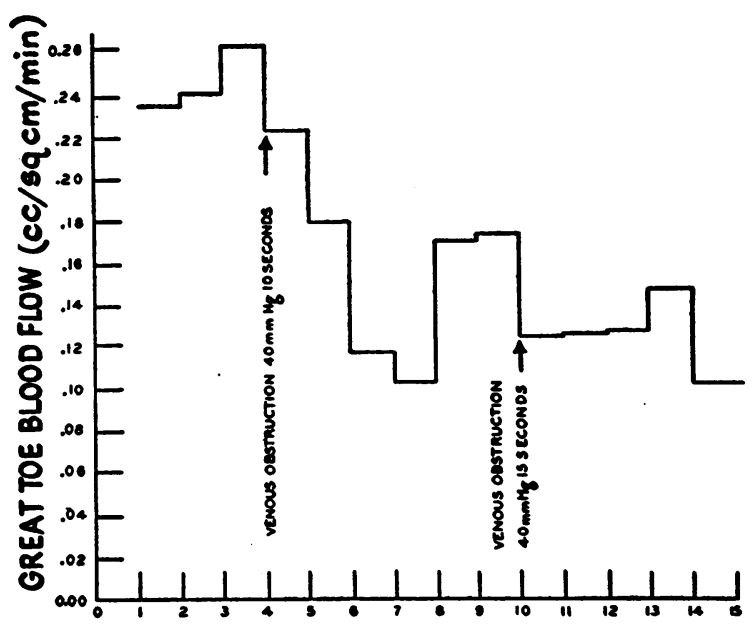

Minutes

Fig. 1. Reflex Vasoconstriction Produced by Venous

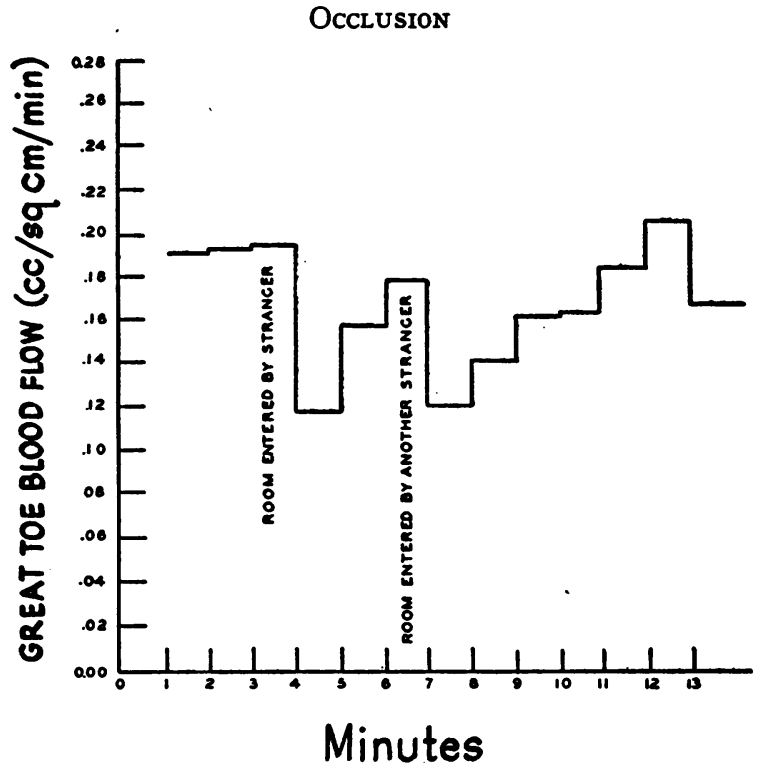

Fig. 2. The Effect of Psychic Stimuli on Digrtal BLOOd Flow (Toz)

pared with blood flow measured during spinal anesthesia in 12 patients. Spinal anesthesia was administered to these patients for surgical operations such as hernioplasty or hemorrhoidectomy. Anesthesia was considered complete when the patient became insensitive to pin prick and was unable to move his lower extremities. One additional patient suffering from causalgia, was studied pre-and two days post-sympathectomy.

\section{RESULTS}

The changes in blood flow after arterial and venous obstruction, in typical experiments, are pre- sented graphically in Figures $3 \mathrm{~A}$ and $\mathrm{B}$. The results in many experiments on upper as well as lower extremities (Tables I and II) confirmed these findings. It will be seen that venous obstruction for several minutes decreased blood flow only slightly, and sometimes not at all; whereas, arterial obstruction reduced blood flow in the fingertip or toe sharply, although not quite to the zero level. The heat of metabolism was calculated

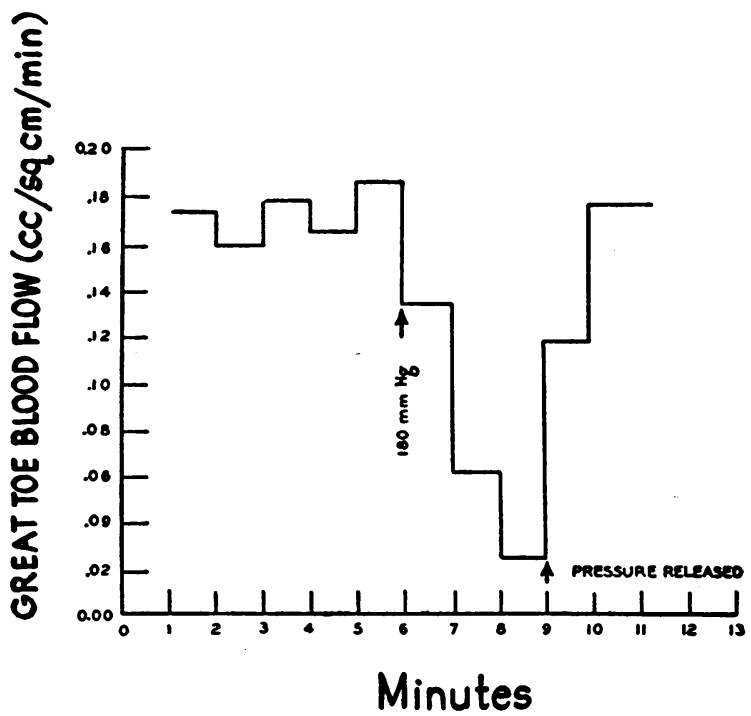

Fig. 3A. The Effect of Arterial Occlusion on Digital Blood Flow (Toe)

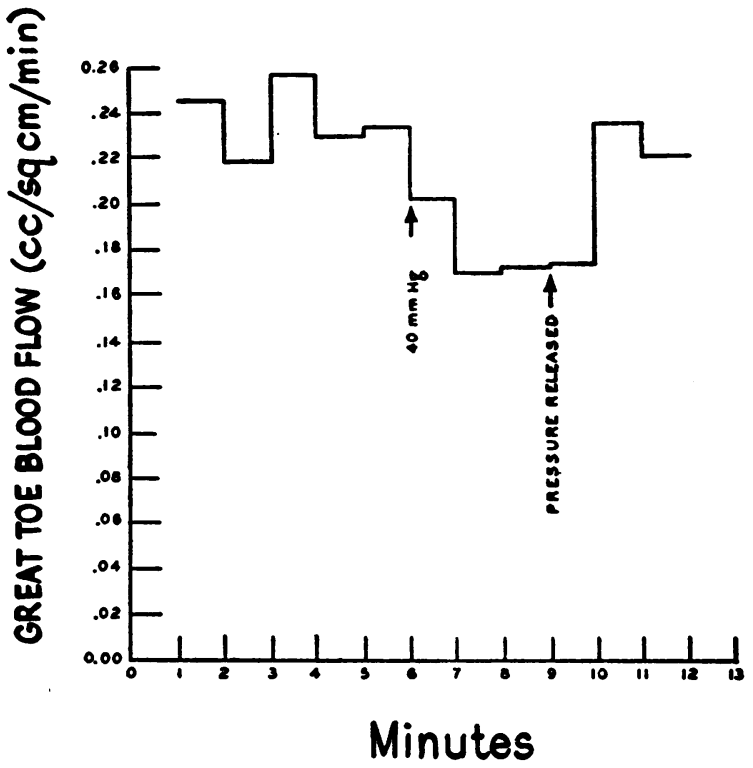

Fig. 3B. The Effect of Venous Occlusion on Digital Blood Flow (Tor) 
TABLE I

The effect of arterial obstruction on digital blood flow

\begin{tabular}{|c|c|c|c|c|c|}
\hline Digit & $\begin{array}{c}\begin{array}{c}\text { Time } \\
\text { of } \\
\text { obstruc- } \\
\text { tion }\end{array} \\
\text {. }\end{array}$ & $\begin{array}{c}\text { Flow } \\
\text { before } \\
\text { obstruc- } \\
\text { tion }\end{array}$ & $\begin{array}{l}\text { Lowest } \\
\text { flow } \\
\text { during } \\
\text { obstruc- } \\
\text { tion }\end{array}$ & $\begin{array}{c}\text { Flow } \\
\text { after } \\
\text { obstruc- } \\
\text { tion }\end{array}$ & $\begin{array}{l}\text { Maximum } \\
\text { per cent } \\
\text { change } \\
\text { in flow }\end{array}$ \\
\hline Great Toe & $\begin{array}{c}\min . \\
9 \\
6 \\
6 \\
3 \\
3 \\
3 \\
3 \\
3 \\
3 \\
3 \\
3 \\
2 \\
2 \\
\frac{1}{2} \\
\frac{1}{2} \\
\frac{1}{2} \\
\frac{1}{2} \\
\frac{1}{2} \\
\frac{1}{2} \\
\frac{1}{2} \\
\frac{1}{2}\end{array}$ & \begin{tabular}{|l} 
cc./sq.cm./ \\
min. \\
0.15 \\
0.18 \\
0.16 \\
0.17 \\
0.18 \\
0.17 \\
0.26 \\
0.16 \\
0.18 \\
0.15 \\
0.17 \\
0.18 \\
0.19 \\
0.26 \\
0.23 \\
0.27 \\
0.20 \\
0.27 \\
0.17 \\
0.24 \\
0.14
\end{tabular} & $\begin{array}{c}\text { cc./sq.cm./ } \\
\text { min. } \\
0.01 \\
0.02 \\
0.02 \\
0.03 \\
0.07 \\
0.02 \\
0.09 \\
0.06 \\
0.04 \\
0.04 \\
0.07 \\
0.07 \\
0.06 \\
0.21 \\
0.18 \\
0.17 \\
0.14 \\
0.20 \\
0.12 \\
0.17 \\
0.11\end{array}$ & $\begin{array}{c}c c . / s q . c m . / \\
\text { min. } \\
0.16 \\
0.15 \\
0.14 \\
0.16 \\
0.21 \\
0.17 \\
0.25 \\
0.20 \\
0.20 \\
0.15 \\
0.12 \\
0.23 \\
0.17 \\
0.23 \\
0.23 \\
0.25 \\
0.20 \\
0.26 \\
0.17 \\
0.27 \\
0.15\end{array}$ & $\begin{array}{l}-93 \\
-89 \\
-88 \\
-82 \\
-61 \\
-88 \\
-65 \\
-63 \\
-78 \\
-73 \\
-59 \\
-61 \\
-68 \\
-19 \\
-22 \\
-37 \\
-30 \\
-26 \\
-29 \\
-29 \\
-21\end{array}$ \\
\hline Finger & $\begin{array}{l}8 \\
3 \\
3 \\
3 \\
3 \\
3 \\
3 \\
\frac{1}{2} \\
\frac{1}{2} \\
\frac{1}{2} \\
\frac{1}{2} \\
\frac{1}{2} \\
\frac{1}{2} \\
\frac{1}{2}\end{array}$ & $\begin{array}{l}0.34 \\
0.32 \\
0.24 \\
0.32 \\
0.12 \\
0.26 \\
0.39 \\
0.31 \\
0.21 \\
0.29 \\
0.27 \\
0.24 \\
0.32 \\
0.30\end{array}$ & $\begin{array}{l}0.07 \\
0.03 \\
0.04 \\
0.03 \\
0.03 \\
0.04 \\
0.05 \\
0.23 \\
0.16 \\
0.23 \\
0.21 \\
0.20 \\
0.22 \\
0.22\end{array}$ & $\begin{array}{l}0.28 \\
0.32 \\
0.25 \\
0.28 \\
0.11 \\
0.24 \\
0.38 \\
0.34 \\
0.23 \\
0.29 \\
0.30 \\
0.24 \\
0.33 \\
0.33\end{array}$ & $\begin{array}{l}-79 \\
-91 \\
-83 \\
-91 \\
-75 \\
-85 \\
-87 \\
-26 \\
-29 \\
-21 \\
-22 \\
-17 \\
-31 \\
-27\end{array}$ \\
\hline
\end{tabular}

to be too small to be measured calorimetrically (3) and hence was not considered responsible for the residual heat elimination during arterial obstruction. With digital vasodilatation, some blood reached the fingertip or toe, probably via deep bone channels, even when the arteries were obstructed at several levels. To obliterate blood flow through the fingertip or toe completely, it was necessary to supplement arterial obstruction at the level of the ankle and toe, or at the level of upper arm, wrist and finger, by reflex vasoconstriction for several minutes (3). Several experiments, in which venous and arterial obstruction were employed for only 30 seconds or less, also revealed less decrease in flow during venous than during arterial obstruction, although the differences were less striking. The "lag" factor of the digital cal- orimeter, however, is approximately one minute and each of the series of flow determinations made in any patient covers a period of one minute. It would therefore be expected that such differences as occur with obstruction over a fraction of a minute would be "damped" to some extent. The lower venous pressure in the initial phase of venous obstruction might also be a "damping" factor.

In Table III, blood flow in the great toe measured calorimetrically after indirect heating supplemented by TEAC is compared with blood flow

TABLE II

The effect of venous obstruction on digital blood flow

\begin{tabular}{|c|c|c|c|c|c|}
\hline Digit & $\begin{array}{c}\text { Time } \\
\text { of } \\
\text { obstruc- } \\
\text { tion }\end{array}$ & $\begin{array}{c}\text { Flow } \\
\text { before } \\
\text { obstruc- } \\
\text { tion }\end{array}$ & $\begin{array}{l}\text { Lowest } \\
\text { flow } \\
\text { during } \\
\text { obstruc- } \\
\text { tion }\end{array}$ & $\begin{array}{c}\text { Flow } \\
\text { after } \\
\text { obstruc- } \\
\text { tion }\end{array}$ & $\begin{array}{c}\text { Maximum } \\
\text { per cent } \\
\text { change } \\
\text { in flow }\end{array}$ \\
\hline Great Toe & $\begin{array}{c}\min . \\
9 \\
4 \\
4 \\
4 \\
3 \\
3 \\
3 \\
3 \\
3 \\
3 \\
2 \\
2 \\
2 \\
2 \\
2 \\
2 \\
\frac{1}{2} \\
\frac{1}{2} \\
\frac{1}{2} \\
\frac{1}{2} \\
\frac{1}{2} \\
\frac{1}{2} \\
\frac{1}{2} \\
\frac{1}{2} \\
\frac{1}{2} \\
\frac{1}{2}\end{array}$ & $\begin{array}{l}\text { cc./sq.cm./ } \\
\text { min. } \\
0.23 \\
0.21 \\
0.08 \\
0.17 \\
0.15 \\
0.05 \\
0.17 \\
0.23 \\
0.15 \\
0.25 \\
0.23 \\
0.13 \\
0.21 \\
0.16 \\
0.16 \\
0.06 \\
0.15 \\
0.12 \\
0.19 \\
0.28 \\
0.19 \\
0.14 \\
0.11 \\
0.17 \\
0.16\end{array}$ & $\begin{array}{c}c c . / s q . c m . / \\
\text { min. } \\
0.14 \\
0.15 \\
0.05 \\
0.14 \\
0.12 \\
0.04 \\
0.11 \\
0.17 \\
0.16 \\
0.18 \\
0.23 \\
0.08 \\
0.18 \\
0.13 \\
0.13 \\
0.06 \\
0.12 \\
0.13 \\
0.18 \\
0.12 \\
0.15 \\
0.14 \\
0.11 \\
0.17 \\
0.16\end{array}$ & $\begin{array}{c}\text { cc./sq.cm./ } \\
\text { min. } \\
0.24 \\
0.30 \\
0.08 \\
0.18 \\
0.14 \\
0.09 \\
0.15 \\
0.23 \\
0.16 \\
0.28 \\
0.26 \\
0.10 \\
0.24 \\
0.16 \\
0.15 \\
0.06 \\
0.16 \\
0.13 \\
0.18 \\
0.30 \\
0.19 \\
0.13 \\
0.11 \\
0.17 \\
0.18\end{array}$ & $\begin{array}{r}-39 \\
-29 \\
-38 \\
-18 \\
-20 \\
-20 \\
-35 \\
-26 \\
+7 \\
-28 \\
0 \\
-38 \\
-14 \\
-19 \\
-19 \\
0 \\
-20 \\
+8 \\
-5 \\
-57 \\
-21 \\
0 \\
0 \\
0 \\
0\end{array}$ \\
\hline Finger & $\begin{array}{l}3 \\
3 \\
3 \\
3 \\
3 \\
3 \\
3 \\
\frac{1}{2} \\
\frac{1}{2} \\
\frac{1}{2} \\
\frac{1}{2} \\
\frac{1}{2}\end{array}$ & $\begin{array}{l}0.28 \\
0.41 \\
0.16 \\
0.20 \\
0.38 \\
0.15 \\
0.23 \\
0.30 \\
0.24 \\
0.35 \\
0.42 \\
0.16 \\
0.26 \\
0.28 \\
0.39 \\
0.25 \\
0.25 \\
0.29 \\
0.28\end{array}$ & $\begin{array}{l}0.26 \\
0.22 \\
0.06 \\
0.18 \\
0.24 \\
0.08 \\
0.18 \\
0.26 \\
0.21 \\
0.31 \\
0.36 \\
0.15 \\
0.23 \\
0.24 \\
0.36 \\
0.21 \\
0.22 \\
0.25 \\
0.22\end{array}$ & $\begin{array}{l}0.32 \\
0.51 \\
0.12 \\
0.22 \\
0.39 \\
0.14 \\
0.19 \\
0.28 \\
0.24 \\
0.38 \\
0.41 \\
0.16 \\
0.26 \\
0.28 \\
0.40 \\
0.23 \\
0.25 \\
0.29 \\
0.27\end{array}$ & $\begin{array}{l}-32 \\
-46 \\
-63 \\
-10 \\
-37 \\
-47 \\
-22 \\
-13 \\
-13 \\
-11 \\
-14 \\
-06 \\
-12 \\
-14 \\
-08 \\
-16 \\
-12 \\
-14 \\
-21\end{array}$ \\
\hline
\end{tabular}


TABLE III

\begin{tabular}{|c|c|c|c|c|c|c|}
\hline \multirow{2}{*}{ Patient } & \multirow{2}{*}{$\begin{array}{l}\text { Age } \\
\text { and } \\
\text { sex }\end{array}$} & \multicolumn{2}{|c|}{$\begin{array}{l}\text { Indirect heating } \\
\text { and TEAC }\end{array}$} & \multicolumn{3}{|c|}{$\begin{array}{l}\text { Spinal anesthesia or } \\
\text { sympathectomy }\end{array}$} \\
\hline & & $\begin{array}{c}\text { Brachial } \\
\text { blood } \\
\text { pressure }\end{array}$ & $\begin{array}{l}\text { Blood } \\
\text { flow }\end{array}$ & $\begin{array}{c}\text { Dosage } \\
\text { pontocaine }\end{array}$ & $\begin{array}{c}\text { Brachial } \\
\text { blood } \\
\text { pressure }\end{array}$ & $\begin{array}{l}\text { Blood } \\
\text { flow }\end{array}$ \\
\hline $\begin{array}{r}1 \\
2 \\
3 \\
4 \\
5 \\
6 \\
7 \\
8 \\
9 \\
10 \\
11 \\
12 \\
13\end{array}$ & $\begin{array}{l}28 \mathrm{M} \\
60 \mathrm{M} \\
15 \mathrm{M} \\
59 \mathrm{~F} \\
66 \mathrm{M} \\
48 \mathrm{~F} \\
55 \mathrm{~F} \\
42 \mathrm{M} \\
24 \mathrm{M} \\
44 \mathrm{~F} \\
29 \mathrm{M} \\
29 \mathrm{M} \\
22 \mathrm{M}\end{array}$ & \begin{tabular}{|c|}
$m m . H g$ \\
$130 / 80$ \\
$128 / 100$ \\
$108 / 64$ \\
$204 / 84$ \\
$132 / 60$ \\
$108 / 64$ \\
$96 / 70$ \\
$92 / 76$ \\
$88 / 70$ \\
$112 / 72$ \\
$82 / 52$ \\
$116 / 80$ \\
$130 / 90$
\end{tabular} & $\begin{array}{c}\text { cc./sq.cm./ } \\
\text { min. } \\
0.15 \\
0.19 \\
0.25 \\
0.14 \\
0.15 \\
0.18 \\
0.16 \\
0.21 \\
0.14 \\
0.23 \\
0.15 \\
0.15 \\
0.21\end{array}$ & $\begin{array}{c}13 \mathrm{mg} . \\
20 \mathrm{mg} . \\
8 \mathrm{mg} . \\
12 \mathrm{mg} . \\
15 \mathrm{mg} . \\
16 \mathrm{mg} . \\
15 \mathrm{mg} . \\
16 \mathrm{mg} . \\
15 \mathrm{mg} . \\
15 \mathrm{mg} . \\
16 \mathrm{mg} . \\
12 \mathrm{mg} . \\
2 \text { days } \\
\text { af ter } \\
\text { sympa- } \\
\text { thectomy }\end{array}$ & \begin{tabular}{|r|}
$m m . H g$ \\
$143 / 85$ \\
$100 / 80$ \\
$118 / 60$ \\
$160 / 80$ \\
$95 / 75$ \\
$100 / 70$ \\
$95 / 75$ \\
$110 / 70$ \\
$90 / 60$ \\
$85 / 70$ \\
$80 / 50$ \\
$108 / 80$ \\
$110 / 72$
\end{tabular} & $\begin{array}{c}\text { cc./sq.cm./ } \\
\text { min. } \\
0.15 \\
0.12 \\
0.08 \\
0.14 \\
0.10 \\
0.14 \\
0.19 \\
0.10 \\
0.15 \\
0.17 \\
0.07 \\
0.20 \\
0.19\end{array}$ \\
\hline
\end{tabular}

during spinal anesthesia in 12 cases and after sympathectomy in one case. With the calorimetric technique blood flow during spinal anesthesia or after sympathectomy was no greater, and in many cases considerably less, than after indirect heating reinforced by TEAC. A decreased systemic blood pressure or circulating vasoconstrictive substances, such as adrenalin, released by the apprehension prior to an operation, might account for the depression of blood flow during spinal anesthesia in those cases in which it occurred. Page, Prince, and Reinhard (11) have shown that circulating vasoconstrictive substances are released from the adrenal medullae and the liver of animals by the intravenous administration of large doses of TEAC. Since the normal range of variation in blood flow is shifted only slightly by supplementing indirect heating by the administration of TEAC intravenously (4) it is unlikely that significant humoral vasoconstriction was induced in our patients by TEAC, in the dosage used.

\section{DISCUSSION}

It is apparent from these experiments that prolonged venous obstruction is incomplete because of considerable reflux of blood probably via deep veins. This reflux may occasionally be great enough to accommodate the total influx from the arteries. Even with 30 seconds of venous obstruction, all the blood is not trapped in the finger or toe. We have no evidence bearing on the first five or 10 seconds of venous obstruction where digital plethysmographic slopes are usually drawn. The calorimetric lag is too great to make successful comparisons of flow at such short intervals. It must be pointed out, however, that reflux of blood may occur even during this initial phase of obstruction, and may produce a variable error in the measurement of blood flow. It has also been demonstrated (12) that at high rates of flow increased pulse volume makes it more difficult to draw accurate digital plethysmographic slopes. In contrast, it is at such high rates of flow that the digital calorimeter becomes most reliable (3). In addition to these factors, it is clear that reflexes induced psychically, or by the very act of venous obstruction, may "break through" the release of sympathetic tone by heating alone and less commonly by heating together with intravenously administered TEAC to distort flow measurements dependent on such obstruction. Since it is less likely that such reflexes can "break through" spinal anesthesia, this factor would also confuse comparison between procedures for releasing sympathetic nerve tone.

In the studies with the foot plethysmograph (7) caudal anesthesia or sympathectomy was compared with heat or TEAC rather than a combination of the two. The combination may be more effective than either of these agents alone in releasing sympathetic nerve tone in the lower extremities. What is more, there may be differences between the reactions of deep blood vessels and those of the skin (7) making comparison between the results of foot plethysmography and digital calorimetry difficult. The fact, however, that spinal anesthesia is no more effective than indirect heating supplemented by TEAC in releasing sympathetic nerve tone, if the calorimetric technique is used, indicates that the latter procedure releases such tone effectively at least in the skin of the toe.

\section{SUMMARY AND CONCLUSIONS}

Spinal anesthesia produces no greater release of sympathetic nerve tone in the great toe than indirect heating supplemented by TEAC when blood flow in the skin is measured calorimetrically. Factors responsible for discrepancies between plethysmographic and calorimetric data were investigated and are discussed. 


\section{ACKNOWLEDGMENT}

Advice of Dr. S. Feitelberg and technical assistance of Miss S. Lichtenberg, Mr. R. E. Schwartz and Mr. G. Grossinger are gratefully acknowledged.

\section{REFERENCES}

1. Mendlowitz, M., Measurements of blood flow and blood pressure in clubbed fingers. J. Clin. Invest., 1941, $20,113$.

2. Capriglione, L. A., and Duque, F. L. V., Da Medida do fluxo sanguineo digital. Arquivos de Clinica, 1948, $7,122$.

3. Mendlowitz, M., Some observations on the calorimetric method for measuring digital blood flow. Angiology, 1950, 1, 247.

4. Mendlowitz, M., and Abel, H. A., Digital blood flow measured calorimetrically in peripheral vascular diseases. In preparation.

5. Wilkins, R. W., Doupe, J., and Newman, H. W., The rate of blood flow in normal fingers. Clin. Sc., 1938, 3, 403.

6. Cooper, K. E., Cross, K. W., Greenfield, A. D. M., Hamilton, D. McK., and Scarborough, H., A com- parison of methods for gauging the blood flow through the hand. Clin. Sc., 1949, 8, 217.

7. Hoobler, S. W., Avera, J. W., Little, W. J., Peet, N. M., and Bassett, R. C., Effect of sympathetic blocking procedures and of sympathectomy on peripheral blood flow. Federation Proc., 1949, 8, 77.

8. Arnott, W. M., and Macfie, J. M., Effect of ulnar nerve block on blood flow in the reflexly vasodilated digit. J. Physiol., 1948, 107, 233.

9. Landowne, M., and Katz, L. N., A critique of the plethysmographic method of measuring blood flow in the extremities of man. Am. Heart J., 1942, 23, 644.

10. Neumann, C., Cohn, A. E., and Burch, G. E., A study of the influence of the character of an examining room on the peripheral blood vessels of normal, hypertensive, and senile subjects. J. Clin. Invest., 1942, 21, 651.

11. Page, I. N., Mechanism of the vascular action of tetraethylammonium chloride. Am. J. Physiol., 1949, 158, 403.

12. Mead, J., and Schoenfeld, R. C., Determination of blood flow through the finger at high rates of flow. Federation Proc., 1949, 8, 108. 